\title{
RESPIRATORY COMPENSATION DURING SPONTANEOUS VENTILATION WITH THE BAIN CIRCUIT
}

\author{
R.J. BYRICK
}

\section{ABSTRACT}

The volume of carbon dioxide rebreathed by spontaneously breathing patients under halothane anaesthesia at various fresh gas flow rates (FGF) with the Bain modification of the Mapleson " $D$ " breathing circuit is measured. The effect of rebreathing on a heterogeneous patient population is shown to be unpredictable hypercapnia in those patients who cannot respond adequately to this carbon dioxide challenge. All adults rebreathe significant volumes of carbon dioxide at a FGF rate of $100 \mathrm{ml} \cdot \mathrm{kg}^{-1} \cdot \mathrm{min}^{-1}$. This carbon dioxide load is a potential risk to every patient and this hypercapnia is preventable by using high FGF rates. Rebreathing occurs because the inspired carbon dioxide load is unpredictable in a given patient and the patient's response is uncontrolled. Patients respond to this carbon dioxide challenge by increasing inspiratory flow rate ( $\mathrm{Vt} / \mathrm{Ti})$, which results in increased rebreathing of carbon dioxide from the expiratory limb of the circuit.

To prevent potentially dangerous rcbrcathing of carbon dioxide in all patients the fresh gas flow rate must be much higher than presently recommended.

The Bain Modification of the Mapleson D circuit has been advocated as a "Universal Circuit" for both controlled and spontaneously breathing patients. The term "universal" implies that, for patients who are judged clinically fit to breathe spontaneously under anaesthesia, there is equivalent patient safety when the Bain circuit is compared to other available circuits.

The fresh gas flow (FGF) rate recommended in the package insert with the Bain circuit is 100 $\mathrm{ml} \cdot \mathrm{kg}^{-1} \cdot \min ^{-1}$ for spontaneous respiration. ${ }^{2}$ This recommended FGF rate for adults is considerably less than that shown by Mapleson ${ }^{3}$ and Conway ${ }^{4}$ to prevent rebreathing of expired carbon dioxide with this type of $\mathbf{T}$-piece circuit. These authors have shown in theoretical models ${ }^{3}$ and in awake volunteers ${ }^{4}$ that a FGF of less than two to two and one half times the patient's minute ventilation ( $\dot{V} E)$ will result in rebreathing. The recommended $F G F$ of $100 \mathrm{ml} \cdot \mathrm{kg}^{-1} \cdot \mathrm{min}^{-1}$ for the Bain circuit is based on data ${ }^{5}$ which demonstrates that healthy young adults undergoing anaesthesia for dental procedures can maintain a "normal" arterial carbon dioxide tension $\left(\mathrm{Pa}_{\mathrm{CO}_{2}}\right)$ of $5.32 \mathrm{kPa}$ (40 torr) by increasing their minute ventilation substantially.

This recommended FGF, which may result in re-breathing in many patients. ${ }^{6}$ has prompted controversy ${ }^{7,8}$ regarding the presence of intact patient responsiveness to an inspired carbon

R.J. Byrick, M.D., F.R.C.P.(C). Department of Anaesthesia, University of Toronto, and St. Michael's Hospital, 30 Bond Street, Toronto, Canada, MSB IW8. dioxide load and the predictability of this response in a heterogenous patient population. The patient and circuit variables which determine the alveolar carbon dioxide tension (hence $\mathrm{Pa}_{\mathrm{CO}_{2}}$ ) in any anaesthetized, spontancously breathing patient have been described.?

A study $y^{7}$ using a lung model demonstrated that the effect of using the recommended FGF would be to increase the inspired carbon dioxide load substantially. The same study also predicted that, in patients with brisk responses to carbon dioxide, an increase in $\dot{V} E$ in response to this inspired carbon dioxide load would result in increased rebreathing from the expiratory limb and the reservoir. The net effect of this ventilatory effort would be little decrease in $\mathrm{Pa}_{\mathrm{CO}_{2}}$; that is, this increased $\dot{V} E$ would be wasted in terms of gas exchange. A more dangerous situation would exist if the patient had a poor ventilatory response to the inspired carbon dioxide, as the $\mathrm{Pa}_{\mathrm{CO}_{2}}$ would rise. The extent of this hypercapnia would be FGF dependent, as the volume of inspired carbon dioxide was determined by the FGF rate.

Because of patient variables such as minute ventilation, respiratory waveform, responsiveness to carbon dioxide and physiological deadspace that are uncontrolled and unpredictable in a spontaneously breathing anaesthetized patient, recommendations for a safe FGF must be made cautiously. The level of FGF must be set to avoid intolerable inspired carbon dioxide loads in all patients.

Canad. Anaesth. Soc. J., vol. 27, no. 2, March 1980 
The purpose of this investigation was to calculate the range of inspired carbon dioxide which results from using the recommended FGF of 100 $\mathrm{ml} \cdot \mathrm{kg}^{-1} \cdot \mathrm{min}^{-1}$ and higher FGF rates, in a heterogenous adult population. We can then discuss the significance of the carbon dioxide load in terms of the respiratory compensation required and consider the consequences of using the recommended FGF rates. The ability of patients to compensate for the carbon dioxide load will then be evaluated.

\section{Method}

Nine healthy patients (ASA 1; age 19 to 65 years; weight 50 to $89 \mathrm{~kg}$ ) undergoing general anaesthesia in the supine position for exploration and repair of peripheral nerve lesions were studied. All patients were examined preoperatively and were considered to be suitable to breathe spontaneously under anaesthesia. No patient had any respiratory disability although four of the nine patients were smokers.

These procedures were chosen because the duration of anaesthesia provided time to study the effects of altering FGF rate and similar patients are frequently allowed to breathe spontaneously during other operations on the upper extremity.

Each unpremedicated patient was given sodium thiopentone 3 to $5 \mathrm{mg} \cdot \mathrm{kg}^{-1}$ to induce anaesthesia. Intubation with a cuffed oral tracheal tube was facilitated by intravenous succinylcholine $1.0 \mathrm{mg} \cdot \mathrm{kg}^{-1}$. Halothane in oxygen was administered using a modified Mapleson D (Bain) circuit. This anaesthetic was chosen to avoid interference by nitrous oxide in the analysis of carbon dioxide tension and halothane levels.

During the study the patient's tracheal tube was attached to a calibrated, heated pneumotachograph, (Fleisch \#2) which was connected to a differential transducer (Statham PM 5). The flow signal from the transducer was used to measure $\mathrm{T}_{\mathrm{t}}$, the duration of inspiration; $\mathrm{T}_{\mathrm{tot}}$, the total respiratory cycle time; and it was integrated electronically to obtain tidal volume. The concentration of carbon dioxide in the respiratory gases was measured using a fast responding Godart capnograph, which continuously sampled gas from a catheter with its tip at the distal end of the tracheal tube. All the variables were recorded on a Mingograph 800 recorder at a paper speed of $25 \mathrm{~mm} / \mathrm{sec}$.

The delay time between sampling carbon dioxide in the trachea and recording the concentration on the Mingograph was determined by

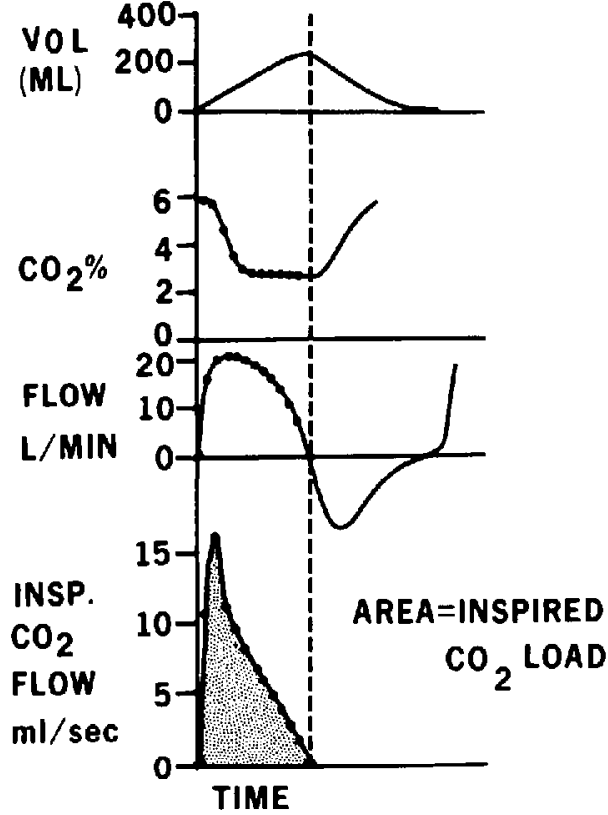

Figure 1 Simultaneous recordings of inspired volume ( $\mathrm{ml})$, inspiratory flow rate ( $/ \mathrm{min})$ and inspired carbon dioxide concentration (per cent) are shown. At 0.08 second intervals during inspiration (dots) the total flow rate is multiplied by the percentage carbon dioxide, the product being the instantaneous inspired carbon dioxide flow ( $\mathrm{ml} / \mathrm{sec}$ ) at that time. The area under the curve formed from these calculated points equals the total volume of carbon dioxide inspired ( $\mathrm{ml} / \mathrm{breath}$ )

connecting the sampling catheter to a balloon filled with five per cent carbon dioxide in air under pressure and connected to a pressure transducer. With the Mingograph recording both signals at a paper speed of $25 \mathrm{~mm} / \mathrm{sec}$, the balloon was slashed, thus producing an immediate decrease in pressure. The time from the drop in pressure to the decrease in carbon dioxide is the delay time. This delay is primarily due to the time taken to aspirate a gas sample through the sampling catheter and it was determined for each patient after each study. Knowledge of the delay time allowed us to shift the carbon dioxide trace so that it was in phase with the flow and volume traces (Figure I).

To determine the inspired carbon dioxide load, the carbon dioxide concentration was calculated at 0.08 second intervals during inspiration and multiplied by the corresponding inspired flow rate (Figure 1). The product is the inspired flow of carbon dioxide at that instant. From this value we derived a curve which represents the inspired 
flow of carbon dioxide in $\mathrm{ml} / \mathrm{sec}$ during a breath (Figure 1). Since the tip of the carbon dioxide sampling catheter was at the distal end of the tracheal tube the calculated inspired carbon dioxide load is the volume of carbon dioxide inspired beyond that point. The area under the curve formed from these points was planimetered to yield the inspired volume of carbon dioxide during that breath (Figure 1). This volume was calculated on at least two representative breaths at each FGF rate studied.

The accuracy of the anaesthetic machine flow-meters, and thus the FGF rates delivered, was verified by passing the fresh gas flow through the pneumotachograph.

Measurements were not made until a stable anaesthetic state suitable for surgery was obtained ( 30 to 40 minutes after induction of anaesthesia) and the first measurement was made 10 to 15 minutes after the initial surgical stimulus. The first measurement was made with the patient receiving the recommended FGF of 100 $\mathrm{ml} \cdot \mathrm{kg}^{-1} \cdot \mathrm{min}^{-1}$. The FGF was then increased to $150 \mathrm{ml} \cdot \mathrm{kg}^{-1} \cdot \mathrm{min}^{-1}$, and later to higher FGF rates. A 10- to 15-minute interval was allowed for stabilization before repeating the measurements at each FGF. After cach recording end-tidal gas was sampled and analyzed for halothane level using a calibrated refractometer.

To ensure that the ventilatory changes recorded were not the result of changing surgical stimulus or anaesthetic duration, the FGF was returned to $100 \mathrm{ml} \cdot \mathrm{kg}^{-1} \cdot \mathrm{min}^{-1}$ after the measurements at high FGF rates were completed. In four patients FGF rates of $70 \mathrm{ml} \cdot \mathrm{kg}^{-1} \cdot \mathrm{min}^{-1}$ were subsequently studied.

In five of the nine patients there was sufficient time to make the same measurements with the patient breathing through a circle system with carbon dioxide absorber at a FGF of $100 \mathrm{ml}$. $\mathrm{kg}^{-1} \cdot \min ^{-1}$.

Data are presented as mean \pm 1 S.E.M. Serial measurements in the same patient are compared to the values obtained at the recommended FGF rate using a paired t-test. If $p<0.05$, the changes are considered significant. An institutional review committee agreed that no formal consent was required from participating patients.

\section{RESULTS}

\section{Carbon dioxide load inspired}

The close relationship between FGF rate and inspired carbon dioxide load in two patients is shown in Figures 2(a) and 2(b). If similar curves

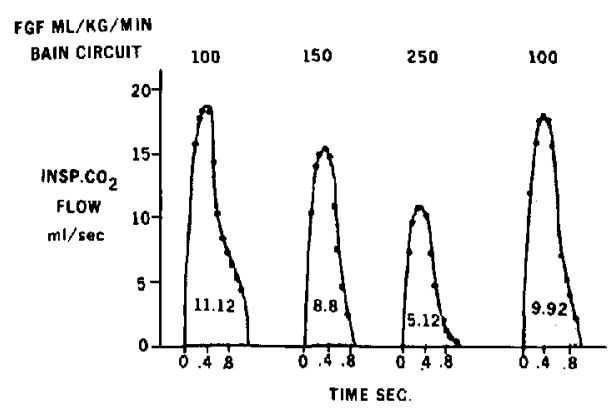

FIGURE 2a Calculaced inspired carbon dioxide load (ml per breath) in a representative patient at variable fresh gas flow (FGF) rates. The initial phase of inspiration contains the greater fraction of the carbon dioxide load, which is reduced as FGF increases.

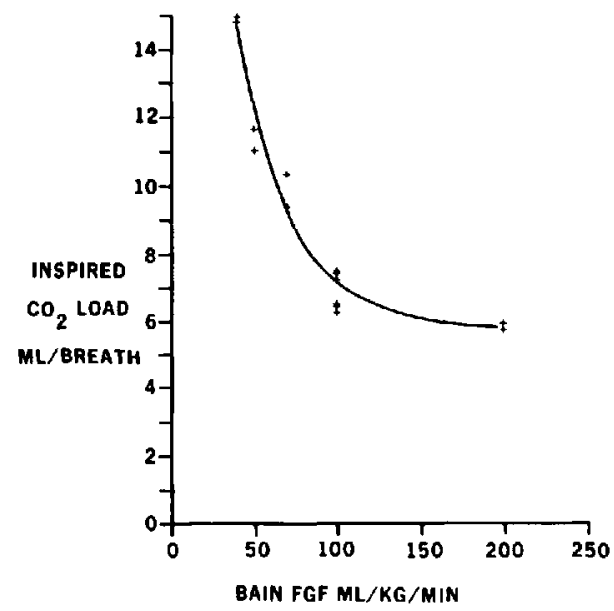

Figure $2 b$ In another representative patient the relationship between FGF rate and calculated inspired carbon dioxide load $(\mathrm{ml} / \mathrm{breath})$ is shown.

are drawn for all nine patients (Figure 3 ) the inspired carbon dioxide load produced by using a FGF rate of $100 \mathrm{ml} \cdot \mathrm{kg}^{-1} \cdot \mathrm{min}^{-1}$ is seen to be highly variable between patients. The average increase in volume of carbon dioxide inspired is 85 per cent (range 14 to 300 per cent) between a FGF rate of $100 \mathrm{ml} \cdot \mathrm{kg}^{-1} \cdot \mathrm{min}^{-1}$ and the highest FGF in these patients. In all nine patients studied, the FGF of $100 \mathrm{ml} \cdot \mathrm{kg}^{-1} \cdot \mathrm{min}^{-1}$ resulted in an increase in the volume of carbon dioxide inspired, above that rebreathed at high FGF rates (Figure 3). Figure 2(a) illustrates that the dis. tribution of the carbon dioxide load is such that the initial part of inspiration contains the greater part of the carbon dioxide. The coefficient of variation of the carbon dioxide load calculation due to measurement error was 5.47 percent when 


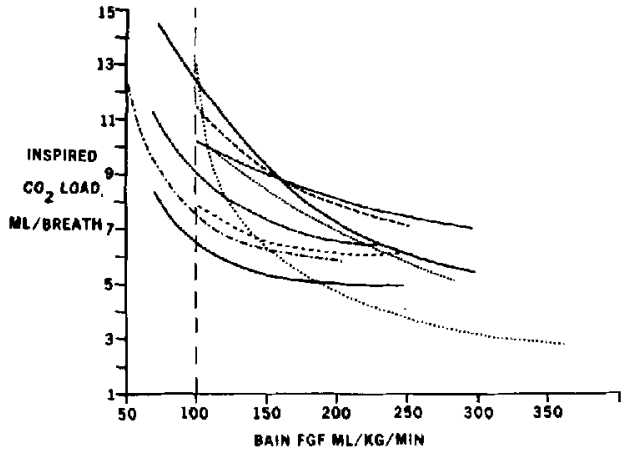

Figure 3 The relationship between FGF rate $\left(\mathrm{ml} \cdot \mathrm{kg}^{-1} \cdot \mathrm{min}^{-1}\right)$ and inspired carbon dioxide load (mi/breath) is plotted in all nine patients studied. The variable and unpredictable increase in inspired carbon dioxide caused by a FGF of $100 \mathrm{ml} \cdot \mathrm{kg}^{-1} \cdot \mathrm{min}^{-1}$ above that present at high FGF rates is shown.

77 sets of duplicate determinations were examined.

II. Ventilatory response to inspired carbon dioxide load

In all nine patients, VE decreased as FGF rate was increased (Figure 4). This decrease in $V_{E}$ was directly related to the carbon dioxide load inspired (Figure 4). The fact that this increased VE (48 per cent above minimal levels present at high FGF rates) returned when FGF was returned to $100 \mathrm{ml} \cdot \mathrm{kg}^{-1} \cdot \mathrm{min}^{-1}$ shows that this response is unlikely to be secondary to anaesthetic time or surgical stimulation. The end-tidal halothane concentrations were constant between measurements (Figure 4). The inspired carbon dioxide load and the minute ventilation of the five paticnts who breathed through a circle system with carbon dioxide absorber are not significantly different from those present with the Bain circuit at high FGF rates. However, both carbon dioxide load and $\dot{V}_{E}$ are significantly lower in all patients with the circle system than when the Bain circuit is used with low FGF $\left(100 \mathrm{ml} \cdot \mathrm{kg}^{-1} \cdot \mathrm{min}^{-1}\right)$.

If the end-tidal carbon dioxide concentration $\left(\mathrm{FET}_{\mathrm{CO}_{2}}\right)$ in a given patient is plotted against the minute volume measured at various FGF rates (Figure 5), one can assess the responsiveness of the patient to low FGF rates. In this patient the rise in $\dot{V} E$ which accompanies a lowering of FGF rate does not prevent a rise in $\mathrm{FET}_{\mathrm{CO}_{2}}$. This rise in $\mathrm{FET}_{\mathrm{CO}}$ is related to the increased inspired carbon dioxide load at reduced FGF rates (right panel, Figure 5).

A similar plot of $\mathrm{FET}_{\mathrm{CO}_{2}}$ at various levels of $\dot{\mathrm{VE}}$ in all nine patients is shown in Figure 6. It can be

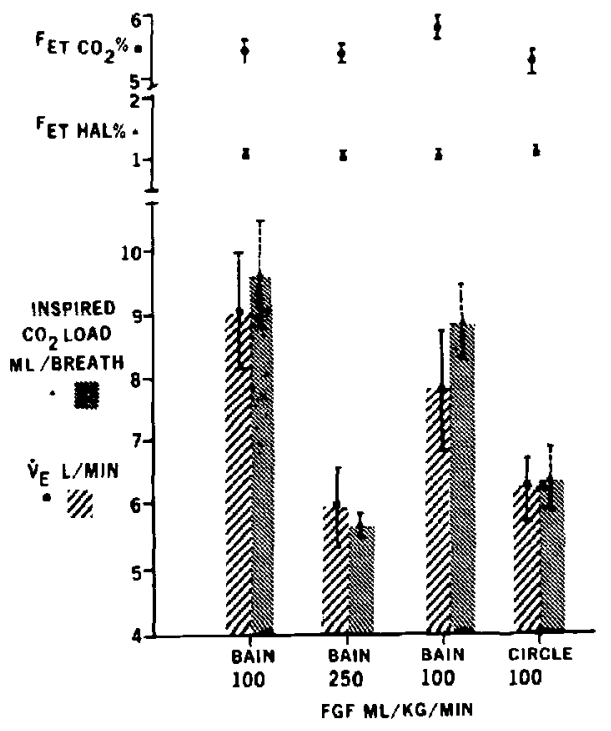

FIGURE 4 Inspired carbon dioxide load (ml/breath) and the minute ventilation ( $\dot{V} E)$ with the Bain Circuit at various FGF rates, compared to a circle system at a FGF rate of $100 \mathrm{ml} \cdot \mathrm{kg}^{-1} \cdot \mathrm{min}^{-1}$. End-tidal halothane and end-tidal carbon dioxide levels at each measurement time are shown for all patients.

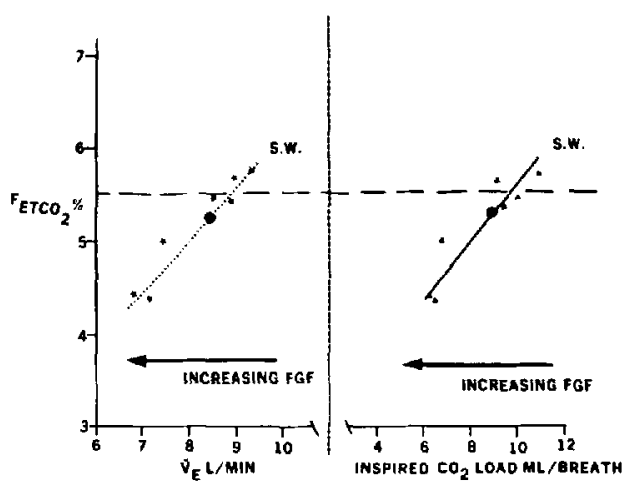

Figure 5 The minute ventilation (VE) and inspired carbon dioxide load at various FGF rates in one patient are shown plotted against the resulting end-tidal carbon dioxide level $\left(\mathrm{FET}_{\mathrm{CO}_{2}}\right)$. The minute ventilation and inspired carbon dioxide load at a FGF of $100 \mathrm{ml} \cdot \mathrm{kg}^{-1} \cdot \mathrm{min}^{-1}$ are illustrated by the dot on each regression line. The measurements made at higher FGF rates are represented by points to the left of the dot on each regression line. Measurements made at lower FGF rates are represented by points to the right of the dot (higher $\mathrm{V}_{E}$, inspired carbon dioxide load and $\mathrm{FET}_{\mathrm{CO}_{2}}$ ).

seen that most patients can maintain an $\mathrm{FET}_{\mathrm{CO}_{2}}$ of approximately 5.5 per cent at a FGF of 100 $\mathrm{ml} \cdot \mathrm{kg}^{-1} \cdot \mathrm{min}^{-1}$ (dots). It is also evident that at high FGF rates the $\mathrm{FET}_{\mathrm{CO}_{2}}$ levels in every patient 


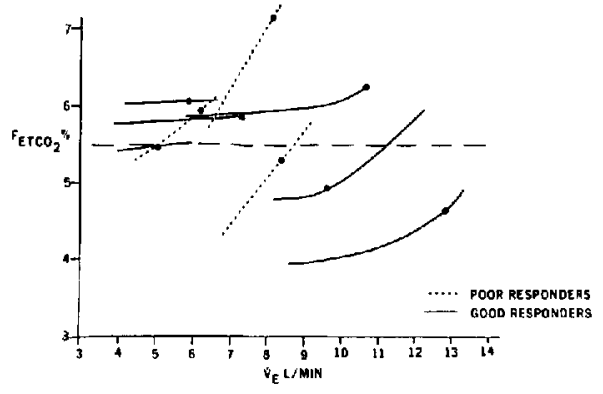

Figure 6 The end-tidal carbon dioxide level $\left(\mathrm{FET}_{\mathrm{CO}_{2}}\right)$ is plotted against the minute ventilation (VE) present at various FGF rates with the Bain Circuit. The end-tidal carbon dioxide and $V E$ present at a FGF rate of $100 \mathrm{ml} \cdot \mathrm{kg}^{-1} \cdot \mathrm{min}^{-1}$ is illustrated by the dot on each curve. The decrease in minute volume at high levels of FGF is represented by the change from the left end of each regression line to the dot. The $\mathrm{FET}_{\mathrm{CO}_{2}}$, and $\mathrm{VE}$ at lower FGF than $100 \mathrm{ml} \cdot \mathrm{kg}^{-1} \cdot \mathrm{min}^{-1}$ are represented by the line to the right of the dot.

are lower (Figure 6) at a reduced $\dot{V}_{E}$ than at a FGF of $100 \mathrm{ml} \cdot \mathrm{kg}^{-1} \cdot \mathrm{min}^{-1}$ represented by the dot on each curve. The degree of hyperpnoea in each patient, which results from the use of FGF rates of $100 \mathrm{ml} \cdot \mathrm{kg}^{-1} \cdot \mathrm{min}^{-1}$ as opposed to the highest FGF tested, is represented by the increment in $V_{c}$ between the left end of each regression line and the dot on the line.

The patients can be arbitrarily divided into two groups on the basis of their response to the inspired carbon dioxide load resulting from the use of the Bain circuit at the recommended FGF. Those patients who increased $\dot{V}_{E}$ and could maintain $\mathrm{FET}_{\mathrm{CO}_{2}}$ relatively constant were separated from those patients whose $\mathrm{FET}_{\mathrm{CO}_{2}}$ increased. The latter group were designated $P$ oor Responders with respect to their $\mathrm{FET}_{\mathrm{CO}_{2}}$ as they could maintain a much lower $\mathrm{FET}_{\mathrm{CO}_{2}}$ at high FGF rates than was possible at a $\mathrm{FGF}$ of $100 \mathrm{ml} \cdot \mathrm{kg}^{-1}$ $\cdot \min ^{-1}$. The severity of hypercapnia (elevated $\mathrm{FET}_{\mathrm{CO}_{2}}$ ) in these patients is determined by the inspired carbon dioxide load which is FGF dependent (Figure 3). The former (and larger) group was designated Poor Responders because the increase in $\dot{V} E$ generated by the inspired carbon dioxide load maintained $\mathrm{FET}_{\mathrm{CO}_{2}}$ relatively constant. The normal response to a significant in-

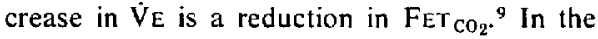
Good Responders any further stimulus to respiratory effort, such as metabolic acidosis, will not be able to decrease carbon dioxide tension proportionally ${ }^{10}$ because of increased rebreathing.

Because we have calculated the inspired car-

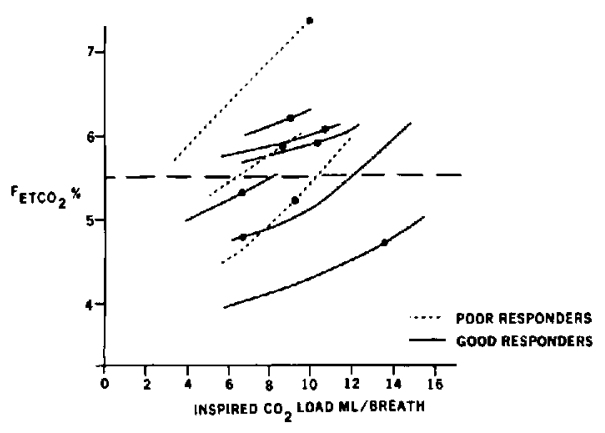

Figure? Cuves for all patients scudied plotting end-tidal carbon dioxide $\left(\mathrm{FET}^{-} \mathrm{CO}_{2}\right)$ against the inspired carbon dioxide load (ml/breath) at various FGF rates with the Bain Circuit are shown. The end-tidal carbon dioxide and carbon dioxide load at a FGF of $100 \mathrm{ml} \cdot \mathrm{kg}^{-1} \cdot \mathrm{min}^{-1}$ is illustrated by the dot on each regression line. The decrease in inspired carbon dioxide load at high levels of FGF is represented by the change from the left end of each regression line to the dot. The $\mathrm{FET}_{\mathrm{CO}_{2}}$ load at lower FGF are represented by the line 10 the right of the dot.

bon dioxide load in each patient and measured the ventilatory response to this challenge, it is possible to evaluate the two patient groups (Good Responders and Poor Responders) with respect to these variables.

III Relationship of end-tidal carbon dioxide concentration to inspired carbon dioxide load

In Figure 7 the $\mathrm{FET}_{\mathrm{CO}_{2}}$ resulting from various inspired carbon dioxide loads in nine patients is plotted. The absolute value of the inspired carbon dioxide load at a FGF of $100 \mathrm{ml} \cdot \mathrm{kg}^{-1}$ . $\min ^{-1}$ (dot on the regression line) is not significantly different in the patients who are hypercapnic ( $\mathrm{FET}_{\mathrm{CO}_{2}}>5.5$ per cent) than those with lower FET con. There is also no significant difference in the volume of carbon dioxide inspired between the Good Responders and the Poor Responders ( $\mathrm{p}>0.5$ - unpaired $\mathrm{t}$-test). The increase in carbon dioxide load inspired (increment in carbon dioxide load from left end of regression line to dot, Figure 7) is not significantly different between Good Responders and Poor Responders.

\section{How do patients respond to this carbon dicxide challenge?}

Figure 8 shows that all nine patients responded to this carbon dioxide challenge by increasing mean inspiratory flow rate $\left(V_{T} / T_{1}\right)$ with no change in the fraction of the respiratory cycle devoted to inspiration ( $T_{1} /$ TTor). The Poor Re- 


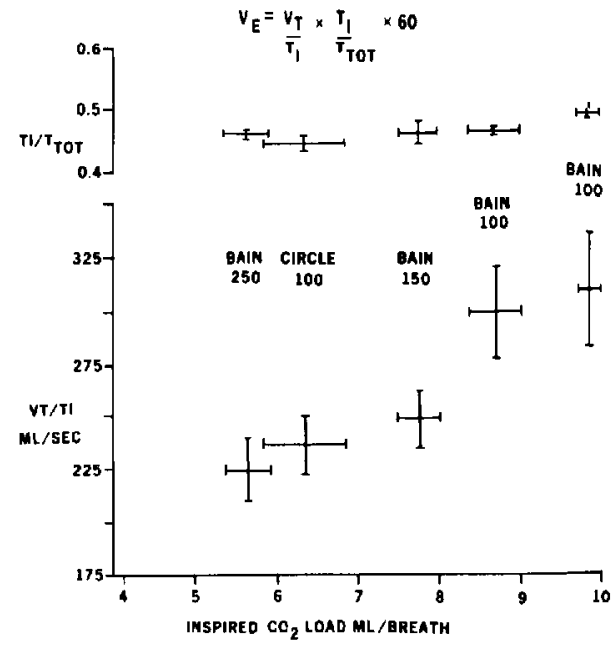

FIGURE 8 The ventilatory response $(\dot{V} E)$ to an inspired carbon dioxide load can be analyzed using concept of mean inspiratory flow rate (VT/TI) and the fraction of time of respiratory cycle devoted to inspiration (TI/Tror). At low FGF rates in the Bain Circuit (high inspired $\mathrm{CO}_{2}$ load) all patients respond by increasing $\mathrm{Vr} / \mathrm{T} \mathrm{I}$ with little change in $\mathrm{T} 1 / \mathrm{T}$ ToT.

sponders increased their mean inspiratory flow rate by $40.2 \pm 3.2 \mathrm{ml} / \mathrm{sec}$ which was significantly less than the Good Responders whose mean increase in VT/TI was $93.8 \pm 11.5 \mathrm{ml} / \mathrm{sec}$. This confirms the impression that the Poor Responders had a reduced responsiveness to inspired carbon dioxide even though the increase in FET $\mathrm{CO}_{2}$ provided a further stimulus to respiratory compensation. Neither the patient's age nor cardiorespiratory history were of any value in distinguishing between these groups.

\section{Discussion}

\section{Patient population}

Based on the data of Spoerel ${ }^{5}$ the recommended FGF rate for the Bain Circuit is 100 $\mathrm{ml} \cdot \mathrm{kg}^{-1} \cdot \mathrm{min}^{-1}$, during spontaneous respiration. There are two major differences between patients reported in this study and those reported by Spoerel: ${ }^{5}$ the age distribution and the use of nitrous oxide in the anaesthetic technique.

The patients reported in this study represent a more heterogeneous population with respect to age (range 19-65) (41.8 \pm 6.1$)$, which would appear to be reasonable if one is attempting to develop recommendations for general use of the circuit. All these patients would have been clinically ASA I and judged suitable for spontaneous breathing for brief procedures, It is apparent from Figure 4 that, if a FGF of $100 \mathrm{ml} \cdot \mathrm{kg}^{-1}$ - min $^{-1}$ had been used, hyperpnoea secondary to the high inspired carbon dioxide load would have been necessary for the duration of the anaesthetic to maintain the $\mathrm{FeT}_{\mathrm{CO}_{2}}$ level measured. The effect on ventilatory compensation of surgical stimuli and anaesthetic duration at low FGF rates are negligible when compared to the effect of the inspired carbon dioxide load (Figure 4). The fact is that hypercapnia, when it occurs, is achieved quickly. If a FGF rate of $100 \mathrm{ml} \cdot \mathrm{kg}^{-1} \cdot \mathrm{min}^{-1}$ is used some Poor Responders will develop respiratory acidosis which could be dangerous for even short procedures.

The anaesthetic technique used is important in evaluating the response of patients to a carbon dioxide load. No patients were pre-medicated. This preserves the ventilatory response to carbon dioxide which would have been depressed by narcotics. ${ }^{12}$ In all patients the trachea was intubated and this decreases the deadspace compared to that present when a mask anaesthetic technique is used which would significantly increase the inspired carbon dioxide load resulting from low FGF rates. ${ }^{13}$ The volume of the pneumotachograph used is $23 \mathrm{ml}$, which is minimal compared to a mask and accompanying airway changes when the trachea is not intubated. Thus the technique used approximates the ventilatory depression and deadspace volume which may be encountered in clinical practice.

The major difference in technique between the two studies is the absence of nitrous oxide in the inspired gases for our study. The fact that both groups could maintain similar levels of $V_{E}$ suggests the overall level of anaesthesia was similar. The waveform was not analyzed in terms of $\mathrm{VT} / \mathrm{Tr}$ and $\mathrm{Tl} / \mathrm{TTOT}$ in previous studies; however the frequency in Spoerel's patients ${ }^{5}(34 \pm 6.0)$ is similar to our patients $(30.0 \pm 1.0)$. Thus the effect on inspired carbon dioxide load of adding nitrous oxide to the anaesthetic technique is probably negligible, when compared to halothane in oxygen.

\section{Carbon dioxide load inspired}

The calculation of inspired carbon dioxide load per breath measures the volume of carbon dioxide inspired beyond the point of sampling. For our patients this point was the distal end of the tracheal tube. Variations in the absolute value of inspired carbon dioxide load between patients reflect many variables including the site of sampling. In any given patient (Figure 2), the change 
in inspired carbon dioxide which results from a change in FGF is a true measure of the extent of rebreathing of expired gas, as the sampling site is constant in any patient. Ungerer ${ }^{6}$ has stated that there is evidence of rebreathing at all FGF rates less than $150 \mathrm{ml} \cdot \mathrm{kg}^{-1} \cdot \mathrm{min}^{-1}$ in his patients. Figure 3 verifies this finding and shows that the FGF at which inspired carbon dioxide load reaches a minimal value (non-rebreathing) varies widely between patients. The magnitude of the increase in carbon dioxide load which results from using a FGF of $100 \mathrm{ml} \cdot \mathrm{kg}^{-1} \cdot \mathrm{min}^{-1}$ is highly unpredictable.

This study deals with the effect of FGF rates on rebreathing during halothane anaesthesia and, as the theoretical determinants of inspired carbon dioxide load are $\dot{V}_{E}$, the respiratory waveform, deadspace, carbon dioxide production and FGF rate, it should be emphasized that other agents may alter the degree of rebreathing by altering one of these variables. It should also be noted that the mean arterial carbon dioxide level is an insensitive guide to the presence or absence of rebreathing (Figure 4). This is consistent with the patient data published by Spoerel. ${ }^{5}$

The importance of any inspired carbon dioxide load is determined by what area of the lung contains the carbon dioxide at end-inspiration. If the carbon dioxide lies in perfused alveoli, there will be significant impairment of carbon dioxide exchange; that is, to maintain the same alveolar carbon dioxide tension the patient must increase minute ventilation (hence alveolar ventilation) significantly. Alternatively, if the carbon dioxide passes to unperfused areas of the lung (deadspace), it will not participate in gas exchange and, for practical purposes, will not be significant to the patient. The significance of an inspired carbon dioxide load to a patient may be assessed by measuring the effect of this load on the relationship between minute volume and $\mathrm{FET}_{\mathrm{CO}_{2} \text {. }}$

III. Compensatory response to carbon dioxide load

All nine patients increased their minute ventilation when a FGF of $100 \mathrm{ml} \cdot \mathrm{kg}^{-1} \cdot \mathrm{min}^{-1}$ was used as compared to high FGF rates (Figure 6). The possible danger (hypercapnia) to single patients in any group can be obscured if only grouped data is analyzed.

The discrepancy between $\mathrm{FET}_{\mathrm{CO}_{2}}$ level and $\mathrm{Pa}_{\mathrm{CO}_{2}}$ is determined by the normal alveolararterial carbon dioxide gradient and the failure of end-tidal gas to reach true equilibrium with al- veolar gas at rapid respiratory rates. Both these effects would result in under-estimation of the existing $\mathrm{PaCO}_{2}$ from $\mathrm{FET}_{\mathrm{CO}_{\mathrm{z}}}$ values.

The concept of respiratory reserve is useful when one considers the ability of a patient to compensate for an inspired carbon dioxide load. For our purposes, a patient's respiratory reserve may be considered to be the maximum ventilatory effort that can be generated to maintain an appropriate $\mathrm{PCO}_{2}$ when confronted with a carbon dioxide load. An increase in $\mathrm{Pa}_{\mathrm{CO}_{2}}$ means the respiratory reserve has been exhausted.

Figure 6 demonstrates that many patients can maintain $\mathrm{FET}_{\mathrm{CO}_{2}}$ near 5.5 per cent by increasing $\dot{V}_{E}$ al a FGF of $100 \mathrm{ml} \cdot \mathrm{kg}^{-1} \cdot \mathrm{min}^{-1}$ (represented by dots). This is consistent with the results of Spoerel's study. ${ }^{5}$ In terms of respiratory reserve, every patient would be able to maintain a lower $\mathrm{FET}_{\mathrm{CO}_{2}}$ with less effort at high FGF rates (represented by the left end of each curve, Figure 6). It is evident in these patients that the degree of compensation required varies widely before exhaustion of the respiratory reserve, which is marked by increasing levels of $\mathrm{FET}_{\mathrm{CO}_{2}}$. The absolute level of $\mathrm{FET}_{\mathrm{CO}_{2}}$ is a poor index of the remaining reserve.

Two basic types of response can be distinguished in these patients. Three of our nine patients developed increasing levels of hypercapnia as the FGF decreased toward 100 $\mathrm{ml} \cdot \mathrm{kg}^{-1} \cdot \mathrm{min}^{-1}$. These patients (Poor Responders) were entirely dependent on a nonrebreathing circuit to maintain minimal $\mathrm{FEr}_{\mathrm{CO}_{2}}$ levels.

The FET $\mathrm{Ca}_{2}$ in the Good Responders did not decrease as $\dot{V}_{E}$ increased. This results from the increased volume of carbon dioxide inspired as VE (and VT/TI) increases (Figure 8). These Good Responders cannot decrease the ir $\mathrm{FET}_{\mathrm{CO}_{2}}$ appropriately below this plateau level even if $V_{E}$ increases in response to a metabolic acid load or similar respiratory stimulus at the low FGF.

Studies using a lung mode ${ }^{7}$ have demonstrated that the prime determinants of the plateau reached by any patient are the physiological deadspace to tidal volume ratio and the FGF rate (Figure 9). The shaded area represents the volume of carbon dioxide inspired at any given level of minute ventilation in the model. It is clear that for any given $V_{D} / V_{T}$ ratio (e.g. 0.65), a patient who can respond to an increased carbon dioxide load will reach a plateau $\mathrm{FET}_{\mathrm{CO}_{2}}$ determined by the FGF rate. One effect of anaesthesia is to increase VD/VT ratio, a result which will be exacerbated by a mask anaesthetic. Since the 


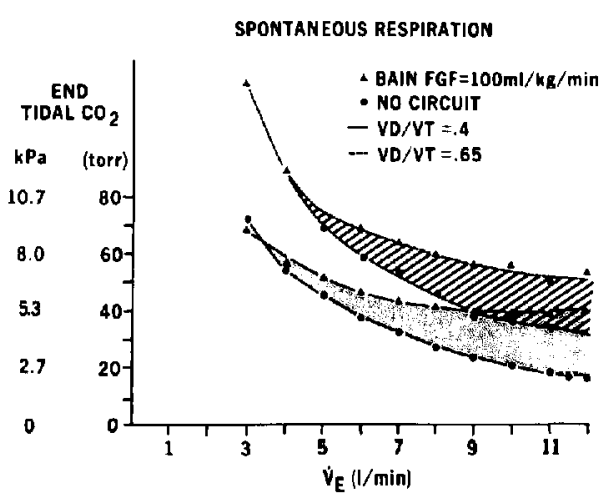

Figure 9 End-tidal carbon dioxide $\left(\mathrm{CO}_{2}\right)$ using a Bain circuit ( $F G F=100 \mathrm{ml} \cdot \mathrm{kg}^{-1} \cdot \mathrm{min}^{-1}$ ) and a nonrebreathing circuil with $V_{D} / V_{T} 0.4$ and 0.65 at different levels of minute ventilation ( $\mathrm{VE}_{\mathrm{E}}\left(\dot{\mathrm{V}}_{\mathrm{CO}}=180 \mathrm{ml} / \mathrm{min}\right.$.) in model lung. Shaded area represents the increase in end-tidal carbon dioxide due to rebreathing at any given $\dot{V}_{E}$ at the recommended FGF rate. (Reproduced with permission of authors and Canad. Anaesth. Soc. J.)

anaesthetist cannot control the $\mathrm{VD}_{\mathrm{D}} / \mathrm{V}_{\mathrm{T}}$ relationship, it follows that he will be unable to predict the plateau value of $\mathrm{PCO}_{2}$. The result of this effect of anaesthesia (increasing $V_{D} / V_{T}$ ) on carbon dioxide exchange can be reduced by increasing the FGF rate.

The lung model study ${ }^{7}$ predicted that the primary response of a patient who was rebreathing significant volumes of carbon dioxide to an increase in FGF would not be a decrease in FET $\mathrm{CO}_{2}$ or $\mathrm{Pa}_{\mathrm{CO}_{2}}$ but rather a large decrease in $\mathrm{VE}$ with a small decrease in FET $\mathrm{CO}_{2}$. The flat slopes of the curves (Figure 6) illustrates that the Good Responders spontaneously decreased minute volume with minimal decreases in $\mathrm{FET}_{\mathrm{CO}_{2}}$. Since the volume of carbon dioxide inspired by patients was not significantly different between the Good Responders and Poor Responders (Figure 7) the major difference must have been the response of the patient to this carbon dioxide load. The level of $\mathrm{FET}_{\mathrm{CO}_{2}}$ could not be predicted nor controlled by the anaesthetist. The patient who became most hypercapnic $\left(\mathrm{FeT}_{\mathrm{CO}_{2}}=7.2\right.$ per cent or 7.18 $\mathrm{kPa}$ [54 torr]) was a 21-year-old smoker (8 cigarettes per day). There were no clinical features to distinguish this patient from the other subjects.

The compensatory increase in minute ventilation that results from using a FGF rate of 100 $\mathrm{ml} \cdot \mathrm{kg}^{-1} \cdot \mathrm{min}^{-1}$ may be evaluated using the analysis of waveform technique described by Milic-Emili. " This analysis separates a given volume $(\dot{V} E)$ into its two components; mean in- spiratory flow rate $\left(\mathrm{VT}_{\mathrm{T}} / \mathrm{T}_{1}\right)$ and respiratory timing (TI/TTOT), such that $\dot{V E}_{\mathrm{E}}=\mathrm{VT}_{\mathrm{T}} / \mathrm{T} \mathrm{I} \times \mathrm{T}_{\mathrm{l}} / \mathrm{TTOT} \times$ 60.

The patient response to the inspired carbon dioxide load which results from a FGF of 100 $\mathrm{ml} \cdot \mathrm{kg}^{-1} \cdot \mathrm{min}^{-1}$ is entirely due to an increase in inspiratory flow rate $\left(V_{T} / T_{I}\right)$ (Figure 8 ). The fraction of the total respiratory cycle time devoted to inspiration ( $\mathrm{T}_{1} / \mathrm{TTOT}_{\text {) }}$ remains constant at all FGF rates, and hence for all carbon dioxide loads evaluated. Figure 8 illustrates that the effect of the patient's attempt to compensate for the inspired carbon dioxide load is to increase inspiratory flow rate. The net result of this increased inspiratory flow rate $(\mathrm{VT} / \mathrm{Tl})$ is to increase the inspired carbon dioxide load, which negates any drop in $\mathrm{FET}_{\mathrm{CO}_{2}}$. This explains the plateau effect achieved; that is, the greater the ventilatory effort to compensate for the inspired carbon dioxide ( $\mathrm{V} E$ or $\mathrm{Vt} / \mathrm{Ti}$ ), the greater the volume of carbon dioxide rebreathed.

When FGF rate was reduced the Poor Responders had a significantly smaller change in inspiratory flow response $\mathrm{Vt} / \mathrm{Ti}$ than the Good Responders. This difference in responsiveness to a similar quantitative carbon dioxide challenge (Figure 7) tends to corroborate the distinction between these groups. In such a small group (nine patients), it is difficult to assess whether, in the entire population, patients will respond in one of two distinct patterns, or whether the entire spectrum of responsiveness is present.

\section{Could hyperpnoea be beneficial?}

It has been suggested ${ }^{5}$ that an increase in minute ventilation in anaesthetized, spontaneously breathing patients may increase lung volume and provide a beneficial reduction in "alveolar collapse". Any evidence of reduced alveolar collapse resulting from this hyperpnoea is lacking. The mean increase in tidal volume in the patients studied was only $50 \mathrm{ml}$ and the magnitude of this increase was variable between patients. The increase in minute volume is achieved by an increase in the absolute value of tidal volume $\left(\mathrm{V}_{\mathrm{T}}\right)$ and/or frequency of respiration.

This theoretical benefit must be weighed against the risk of hypercapnia in such circumstances. Goodwin ${ }^{15}$ has reported similar variability in $\mathrm{Pa}_{\mathrm{CO}_{2}}$ (36.2 to 63.2 torr -4.81 to 8.41 $\mathrm{kPa}$ ) in subjects who were ASA I clinical status. In patients who become hypercapnic, a proportional increase in hydrogen ion concentration can result in severe acidaemia. ${ }^{16}$ These data suggest that even the patients who can respond to the 
inspired carbon dioxide load are restricted in their ability to compensate normally to the stress of a metabolic acid load. ${ }^{10} \mathrm{~A}$ recent report ${ }^{17}$ of an error of up to 20 per cent in the FGF delivered from rotameters on anaesthetic machines which had been well serviced makes the danger of reduced FGF rates even more significant. Any unrecognized decrease below $100 \mathrm{ml} \cdot \mathrm{kg}^{-1} \cdot \mathrm{min}^{-1}$ in the FGF as a result of mechanical or human error would result in very significant degrees of rebreathing (Figure 3) in most patients because of the relationship between FGF and the inspired carbon dioxide load.

In terms of equivalent patient safety, the theoretical benefit of hyperpnoea resulting from a FGF rate of $100 \mathrm{ml} \cdot \mathrm{kg}^{-1} \cdot \mathrm{min}^{-1}$ would seem to be far less than the very real dangers of hypercapnia and reduced respiratory reserve which result.

\section{Conclusion}

The key determinants of the fraction of carbon dioxide in alveolar gas are represented by the equation:

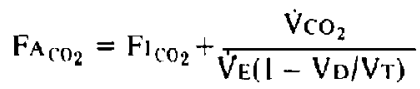

$$
\begin{aligned}
& \mathrm{F}_{\mathrm{A} \mathrm{C}_{2}}=\text { alveolar carbon dioxide fraction } \\
& \mathrm{FI}_{\mathrm{CO}_{2}}=\text { inspired carbon dioxide fraction } \\
& \dot{\mathrm{V}} \mathrm{CO}_{2}=\text { carbon dioxide production } \\
& \dot{V}_{E}=\text { minute ventilation } \\
& V_{D} / V_{T}=\text { physiological deadspace/tidal volume }
\end{aligned}
$$

Of these variables minute volume (VE) because of uncontrolled carbon dioxide responsiveness ${ }^{18}$, $V_{D} / V_{T}$ ratio $^{19}$, and carbon dioxide production ${ }^{20}$ are all dictated by the patient. The only control the anaesthetist has of the alveolar tension $\left(\mathrm{FA}_{\mathrm{CO}_{2}}\right)$ is to reduce the inspired carbon dioxide load $\left(\mathrm{Fl}_{\mathrm{CO}_{2}}\right)$ to a minimal value. This can be accomplished in every patient with the Bain circuit only at high FGF rates. Control of FGF rate, even at high FGF rates, in no way leads to predictable carbon dioxide levels during spontaneous breathing in a heterogeneous patient population because of the many uncontrolled patient variables.

These data'show that all adults under halothane anaesthesia rebreathe significant volumes of carbon dioxide when the Bain circuit is used for spontaneous respiration at the recommended FGF rate. This rebreathing is a potential risk to every patient and some patients with poor carbon dioxide responsiveness are exposed to preventable hypercapnia. This occurs because the inspired carbon dioxide load is unpredictable and the patient's response to this challenge under anaesthesia is uncontrolled. Therefore, in terms of equivalent patient safety for all patients, this circuit can be termed "universal" for spontaneous respiration under halothane anaesthesia only at high FGF rates.

\section{ACKNOWLEDGEMENTS}

The author appreciates the technical assistance of Miss E. Janssen, Mr. C. Kay and Mr. G. Caskenette, without whom this work would not have been possible. The financial assistance from Ohio Medical Products made available the necessary equipment. The co-operation of Dr. Allan Hudson, whose patients were studied, is much appreciated, as well as that of other colleagues with whom this work was discussed. The assistance of Miss C. Mindorff and Mrs. P. Slusarenko in preparing the manuscript is gratefully acknowledged.

\section{REFERENCES}

1. Henville, J.D. \& ADams, A.P. The Bain anaesthetic system. Anaesthesia 31: 247 (1976).

2. Bain Breathing Circuit - Respiratory Care Inc., Arlington Heights Illinois.

3. Mapleson, W.W. The elimination of rebreathing in various anaesthetic systems. Brit. J. Anaesth. 26: 323 (1954).

4. Conway, W.E., Conway, C.M. \& Seleley, N.F. Spontaneous ventilation with the Bain anaesthetic system. Brit. J. Anaesth. 49: 1245 (1977).

5. Spoerel. W.E., Aitken, R.R. \& Bain, J.A. Spontaneous respiration with the Bain breathing circuit. Canad. Anaesth. Soc. J. 25: 30 (1978).

6. UNGERER, M.J. A comparison between the Bain and Magill systems during spontaneous breathing. Canad. Anaesth. Soc. J. 25: 122 (1978).

7. Rose, D. K., Byrick, R.J. \& Froese, A.B. Carton dioxide elimination during spontaneous ventilation with a modified Mapleson D system: studies in a lung model. Canad. Anaesth. Soc. J. 25: 353 (1978).

8. BAin, J.A. \& SPOEREL, W.E. Bain circuit - Letter to the Editor. Canad. Anaesth. Soc, J. 26: 65 (1979).

9. NUNN, J.F. Applied respiratory physiology, 2nd ed. London, Butterworths (1977).

10. Albert, M.S., Dell, R.B. \& Winters, R.W. Quantitative displacement of acid-base equilibrium in metabolic acidosis. Ann. Intern. Med. 66: 312 (1967).

11. Milic-Emilı, J. \& Grunstein. M.M. Drive and timing components of ventilation. Chest (Suppl.) 70: $181(1975)$. 
12. Weil. J.V.. MCCULlough, E., KLINe, J.S. \& SODEL, I.E. Diminished ventilatory response to hypoxia and hypercapnia after morphine in normal man. N. Engl. J. Med. 292: 1103 (1975)

13. Kain, M.L., Panday, J. \& NUnN, J.F. The effect of intubation on the deadspace during halothane anaesthesia. Brit. J. Anaesth. 41: 94 (1969).

14. Goodwin. K. The Bain Circuit - Letter to the Editor. Canad. Anaesth. Soc. J. 23: 675 (1976)

15. Brackett, N.C., Cohen, J.J. \& Schwartz, W.B. Carbon dioxide titration curve in normal man: effect of increasing degrees of acute hypercapnia on acid-base equilibrium. N. Engl. J. Med. 272: 6(1965).
16. Rose, D.K. \& Froese, A.B. The regulation of $\mathrm{Pa}_{\mathrm{CO}_{2}}$ during controlled ventilation of children with a T-piece. Canad. Anaesth. Soc. J. 26: 104 (1979).

17. Munson, E.S., larson, P.C., Babad, A.A., Regan, M.J., Bleuchel, O.R. \& Eger, E.I. The effects of halothane, fluoxene and cyclopropane on ventilation: a comparative study in man. Anesthesiology 27: 716 (1966)

18. NUNN, J.F. \& HILL, D.W. Respiratory deadspace and arterial to end-tidal $\mathrm{CO}_{2}$ tension difference in anaesthetized man. J. Appl. Physiol. 15:583 (1960)

19. Bain, J.A. \& Spoerel. W.E. Carban diaxide output in anaesthesia. Canad. Anaesth. Soc. J. 23: 153 (1976).

\section{RÉSUMÉ}

On a mesuré le volume de $\mathrm{CO}_{2}$ réinspiré avec divers débits de gaz frais, chez des patients anesthésiés à l'halothane, en ventilation spontanée dans un circuit de Bain. Dans ces conditions, on retrouve une hypercapnée d'importance non prévisible chez ceux qui ne présentent pas une réponse adéquate de $\mathrm{CO}_{2}$. Avec un appor de gaz frais de $100 \mathrm{ml} \cdot \mathrm{kg}^{-1} \cdot \mathrm{min}^{-1}$, il y a rebreathing significatif de $\mathrm{CO}_{2}$ chez tous les adultes. Cette situation constitue un risque potential et peut être prévenue par des débits de gaz frais plus élevés. Il y a rebreathing parce que le volume de $\mathrm{CO}_{2}$ produit n'est pas prédictible, de même que la réponse individuelle au $\mathrm{CO}_{2}$. La réponse à une élévation de la $\mathrm{Pa}_{\mathrm{CO}_{2}}$ consiste en une augmentation de la vitesse du dćbit inspiratoire, ce qui augmente encore le rebreathing. En conclusion, pour prévenir un rebreathing important avec hypercarbie, les débits de gaz frais chez l'adulte devraient être plus éle vés que ceux recommandés actuellement. 